\title{
Factors Affecting Adoption of Recommended Cauliflower Production Technology in Nepal
}

\author{
Pankaj Raj Dhital*, Narayan Raj Joshi \\ Department of Agricultural Extension and Rural Sociology, Agriculture and Forestry University, Nepal \\ A R T I C L E I N F O \\ Article history: \\ Received 21 December 2015 \\ Accepted 18 April 2016 \\ Available online, ISSN: 2148-127X \\ Keywords: \\ Personal Factors \\ Technology \\ Adoption \\ Cauliflower \\ Production \\ "Corresponding Author: \\ E-mail: spankajtk@gmail.com

A B S T R A C T \\ Binary logit regression model of econometrics was used to identify the factors affecting \\ adoption of recommended agricultural technology by the commercial farmers of Nepal. A \\ survey was carried out in 2012 in 120 households from Kavre district, Nepal. The \\ objective was to appraise factors affecting adoption of recommended technology of \\ cauliflower, finding out the level of adoption, identifying the constraints of cauliflower \\ cultivation, assessing the perceived level of satisfaction and studying the relationship of \\ certain selected variables on the adoption. Education, Occupation, contact with Personal \\ Localite sources of information, Group membership and Experience were the most \\ influencing factors for adoption of recommended technology. Though, other factors were \\ not strong enough to contribute significantly but indirectly influence the adoption \\ decision of farmers as combined effects. Occupation was found as negatively associated. \\ Landholding size was strongly and positively influencing among the non significant \\ factors. The level of satisfaction and the constraints of cauliflower production were also \\ identified. Transfer of technology will be effective if and only if the client adopts the \\ technology. For an effective transfer of technology, it is better to go for activities for the \\ welfare of the socioeconomic factors of the farmers.
}

\section{Introduction}

Cauliflower (Brassica oleracea L. var. botrytis) is one of the most important and highly preferred vegetable in Nepalese kitchen. The total area covered by cauliflower in Nepal is 25,678 ha and a total production of $362,541 \mathrm{mt}$ with the highest productivity in Dhankuta (17.78 metric tonnes $\left.\mathrm{ha}^{-1}\right)$ and the lowest productivity $\left(3.5 \mathrm{mt} \mathrm{ha}^{-1}\right)$ in Mugu district (VDD, 2007). Similarly, according to VDD (2008) cauliflower was cultivated in 379 ha in Kavre district with production of $4996 \mathrm{mt}$ and productivity of $13.18 \mathrm{mt} \mathrm{ha}^{-1}$ which was nearly $14 \%$ lower than that of the national average.

There is difference between the recommended technology by the research system and its adoption in the farmers' level. The knowledge on the factors affecting the adoption will help in enhancing the process of need based and demand driven technologies generation. Several personal, social, situational characteristics of farmers directly or indirectly affect the adoption of modern technologies along with the perceived characteristics of the innovation by the farmers. This research was conducted to assess factors affecting adoption of recommended agricultural technology with specific objectives of finding out the level of adoption, studying the relationship of certain selected personal, socioeconomic, communication and physical environmental factors on the adoption of those recommended technologies.

\section{Materials and Methods}

A sample of 120 cauliflower growing commercial farmers from Kavre district of Nepal was selected. Information on a range of different variables like demographic factors, socioeconomic and cultural factors and sources of agricultural information were collected. To differentiate the level of adoption of farmers the adopters of technology were classified under two categories as either medium adopter or high adopter by using the Adoption Index (AI). Non adopters were not taken as the samples because the study was conducted not to identify the reason of non-adoption but to access the factors that affect the level of adoption. The adoption index was calculated from the adoption score. The adoption score was calculated by the sum of scores for adoption of five different practices of cauliflower production. On the basis of value of AI, the respondents were grouped into two categories i.e. medium adopters (less than average) and high adopters (more than average). Adoption Index is the degree to which an innovation is adopted by the farmer. Based on the index value, the farmers are thus categorized under two categories. Adoption Index was calculated as (Dongol, 2004):

$$
\mathrm{AI}=\frac{\mathrm{TAF}}{\mathrm{MSO}} \times 100 \%
$$


Where;

AI : Adoption Index

TAF : Total adoption score obtained by an individual farmer

MSO: Maximum score one can obtain

\section{Category of Adopters}

Medium adopter: Medium Adopter doesn't mean that the farmer is not adopting the recommended practices or adopting in lower level but refers to the farmers who had got the value of Adoption Index (AI) below the average of the total farmers.

High adopter: High adopter refers to the farmers who had got value of Adoption Index (AI) above or higher than the average of the total farmers.

\section{Description of Variables and Data Used}

For the logit regression model, the explanatory variables were selected and used to determine the factors affecting adoption. The variables used for the study are explained in table 1 .

The expected signs of Age, Gender, Livestock and Occupation are ambiguous. A household with large family size is expected to have more numbers of persons to work in the field, thus will help to have more areas and latest technologies adopted. So, positive relationship between Family and adoption is expected. The relationship between adoption and Landholding, Experience and Group was hypothesized to be positive. The adoption is found to be mostly positively affected by the personal sources of information than the mass media. Thus the relationship of personal localite and personal cosmopolite sources of information was expected to be positive but for mass media it is uncertain. Adoption is also expected to be positively influenced by the level of formal education as argued by De Souza et al. (1993) and Kattel (2009) stating a more educated farmer is more likely to adopt a new technology.

\section{Description of the Model Used}

Logit regression model was used to investigate the determinants of the farmers' decision of adopting the recommended technology. In the basic model, let $Y_{\mathrm{i}}$ be the binary response of a farmer and can take one of two possible values: $Y=1$ if the farmer is the high adopter and $Y=0$ if medium adopter. Suppose $X$ is a vector of explanatory variable contributing to the adoption decision of the recommended technology and $\beta$ represents the vector of slope parameters associated with the factors $X$ measuring the change in $X$ on the probability of the producer's decision to adopt the technology. The probability of the binary response is defined as follows:

$$
\begin{array}{ll}
\text { If } Y_{\mathrm{i}}=1 ; & \mathrm{P}\left(Y_{\mathrm{i}}=1\right)=\mathrm{P}_{\mathrm{i}} \\
Y_{\mathrm{i}}=0 ; & \mathrm{P}\left(Y_{\mathrm{i}}=0\right)=1-\mathrm{P}_{\mathrm{i}}
\end{array}
$$

Where;

$$
\mathrm{P}_{\mathrm{i}}=\mathrm{E}\left(Y=\frac{1}{X}\right)
$$

represents the conditional mean of $\mathrm{Y}$ given certain values of $X$. (where $\mathrm{X}$ is Sex, Age, Education, Occupation,
Family size, Livestock, Landholding, Group involvement, Experience and Sources of information i.e. Personal Localite, Personal Cosmopolite, Mass Media)

Thus, the probability of adopting the technology then expressed as (Hosmer and Lemeshow, 2000):

$$
\mathrm{P}\left(Y_{\mathrm{i}}=1\right)=\mathrm{P}_{\mathrm{i}}=\frac{1}{1+\exp ^{-\mathrm{z}}} .
$$

Where;

$$
\mathrm{Z}=\alpha+\Sigma \beta_{\mathrm{i}} X_{\mathrm{i}}+\varepsilon_{\mathrm{I}}
$$

The logit transformation of the probability of adoption decision of the recommended technology, $\mathrm{P}\left(Y_{\mathrm{i}}=1\right)$ can be represented as follows (following Gujarati, 2003):

$$
\mathrm{L}_{\mathrm{i}}=\ln \left[\frac{P i}{1-P i}\right]=\mathrm{Z}_{\mathrm{i}}=\alpha+\sum_{i=1}^{n} \quad \beta_{\mathrm{i}} X_{\mathrm{i}}+\varepsilon_{\mathrm{I}}
$$

Where;

$Y_{\mathrm{i}}=$ (Adoption of Technology) Dichotomous dependent variable (i.e. 1 if the farmer is high adopter; and 0 if not a high adopter i.e. for medium adopter)

$X_{\mathrm{i}}=$ Vector of variables included in the logit model,

$\beta_{\mathrm{i}} \quad=$ Parameters to be estimated,

$\varepsilon_{\mathrm{I}} \quad=$ error term of the model,

$\exp (\mathrm{e})=$ base of natural logarithms $(\ln )$,

$\mathrm{L}_{\mathrm{i}} \quad=$ Logit and $\mathrm{P}_{\mathrm{i}} /\left(1-\mathrm{P}_{\mathrm{i}}\right)=$ Odd ratios.

Thus the binary model used in the study was specified implicitly and explicitly as follows:

$Y_{\mathrm{i}}=f$ (Gender, Age, Education, Family size, Livestock, Landholding, Occupation, Experience, Personal, Localite, PersonalCosmopolite, MassMedia, Group)

Age, Education, Family size, Livestock, Landholding, Localite, Cosmopolite, Mass and Experience were continuous variables and the rest (viz. Gender, Occupation and Group) were certified as dummy variables.

During the estimation procedure, a sample estimate of the correlation to check the collinearity problem and Breusch-Pagen Test to test Heteroscedasticity was carried out. The post estimation tests viz. Hosmer-Lemeshow goodness- of -fit test, model discrimination and the link test were performed to check specification errors or omitted variables in logistic regression.

\section{Results and Discussion}

\section{Socio-Demographic Characteristics}

The female-headed household in the study area was $17.5 \%$ and $82.5 \%$ were male entrepreneurs. Majorities $(71.67 \%)$ of the farmers were adult and numbers of young $(15.00 \%)$ and old farmers $(13.33 \%)$ were nearly equal. The average age of the farmers was 37.98. Two third $(62.50 \%)$ of the farmers had nuclear family.

More than $85 \%$ of the total farmers were literate. Agriculture (including livestock) was obviously the major 
occupation of the respondents because they were all commercial farmers. Nearly $40 \%$ farmers had secondary occupation. About two third (63.33\%) of the farmers were members in farmer's group or organizations. The average size of land holding was 0.59 ha, which is less than the national average holding 0.79 ha (CBS, 2007) and district average of 0.68 ha (CBS, 2008). The average year of experience of commercial farming of cauliflower for the farmers was 6.30 years.

\section{Adoption Index (AI) and the Level of Adoption}

The average value of adoption index (A.I.) was $74.01 \%$. None of the farmers had Adoption Index exactly equal to the average AI. Thus the farmers were categorized as follows:

a. Medium Adopters: Farmers with A.I. less than $74.01 \%$, and

b. High Adopters: Farmers with A.I. more than $74.01 \%$

Among the total farmers, $48.33 \%$ of the farmers were medium adopters and $51.67 \%$ were high adopters.

\section{Adoption of the Recommended Technology}

The analysis was focused on the factors affecting the level of adoption of the recommended cauliflower producing technologies. The association selected variables (as in table 1) and the level of adoption was studied. The result of the regression analysis is presented in the table 2. The good explanatory power of the model at $1 \%$ level is indicated by the Wald test (Wald Chi square $=34.26$ ). The Pseudo $\mathrm{R}^{2}$ is 0.3145 . The overall predictive power of the model is $79.17 \%$ and the explanatory power is $31.45 \%$ which are quite high. The results from the Hosmer-Lemeshow' goodness-of-fit shows a Chi-square with a large $\mathrm{P}$ value which indicates that the model presents a good adequacy and fits the data well. The area under ROC curve for the regression is 0.8451 which divulge that the model present satisfactory discrimination. The results according to our expectation i.e.: hat is significant while hats $q$ is not are presented by the link test. It means that the model doesn't have relevant omitted variables. The interpretation based on the coefficients in a logit model that presents a linear regression of the z-score of decision probability on the independent variables can be problematic. So, marginal effect has been driven from the regression coefficients, calculated from a partial derivative as a marginal probability.

The econometric estimates show that the level of adoption of the technology was determined by the Level of Education, Frequency of contact with personal localite sources of information, involvement of the farmer in farmers' group or associations and years of experience in commercial cauliflower cultivation. These variables have the positive and significant association with the adoption of recommended technology. Similarly, involvement of the farmer in off farm occupation along with agriculture as the major source of income also has significant but negative influence on the adoption.
The more educated farmers were more likely to adopt the recommended technology. Ceteris paribus, when the year of education of the farmer increases by one year, there would be an increase in probability that the farmer be a high adopter of the technology by about $2.6 \%$. This may be because, the better educated farmers are more aware of the production and also they are more exposed to the technology and are able to better understand the technologies for commercialization of their farm. Similar findings was given by Kattel (2009) who stated that the probability of a farmer to decide on the adoption of technology increases by about $2 \%$ for every unit increase in the year of education. According to De Souza et al. (1993), farmers with at least a high school education have a $20 \%$ increase in the likelihood of adoption. This finding is also in line with the past reports by Mussei et al. (2001), Ward et al. (2008) and Adjaye (2008).

A positive and significant influence of the frequency of contact of farmer with personal localite source of information on adopting the recommended technology was also found. For a farmer being frequently in contact with any personal localite source of information, the probability of the farmer to be a high adopter increases by $35 \%$. This is because personal localite sources of information are most close and the most believed source of information by the farmers. Roger (1965), Gross (1949), Lionberger (1960), Bose (1964) and Dongol (1979) also stated the positive significant relation between frequency of contact of the farmer with personal localite source of information and the level of adoption of a farmer.

The involvement of the farmer in the group or organizations related to agriculture has highly significant and positive influence on the adoption of the recommended technology. It was also seen that the probability of a farmer being high adopter increases by about $38 \%$ if a member of a farmers' group. The farmers in a group tend to come together with a commitment and a sense of direction and plan for the future. Farmers' in a group learn together and collectively bargainfor opportunities, so they can adopt the appropriate technologies. They exchange skill, knowledge and information among each other and also with the external sources of information. So the farmers involved in group or association are mostly high adopters of the innovation. Lawal and Oluyole (2008), Chi (2008) and Sebadieta (2007) also found similar findings of positive and significant relationship between membership of an organization and the adoption of the technology.

Farming experience was also found to be positively and significantly associated with the level of adoption. The unit increases in farmer's experience increase the probability adoption of the recommended technologies of cauliflower production by 0.040 . It is because the households with past experiences of commercial farming are able to better control the risks and thus adoption might be positively associated. Kavia et al. (2007) also found the increase in the adoption of the improved cassava varieties in larger area by 0.140 per unit increase in farmer's year of experience. Similarly Makokha et al. (2007) found past farming experience positively associated with the adoption of dairy technology. 
Table 1 List of variables for the econometric analysis

\begin{tabular}{|c|c|c|c|}
\hline Variables & Description & Value & Expected Sign \\
\hline 1. Age & Age of the farmer & Year & $+/-$ \\
\hline 2. Gender & Biological Sex & $=1$ for Male, 0 otherwise & $+/-$ \\
\hline 3. FamilySize & Family size & $\begin{array}{l}\text { Number (number of young, adult } \\
\text { and elderly in the } \mathrm{HH} \text { ) }\end{array}$ & + \\
\hline 4. Education & Level of Education & Years of schooling & + \\
\hline 5. Occupation & Farmers' Occupation & $\begin{array}{l}=0 \text { only agriculture; } 1=\text { if involved } \\
\text { in any off farm occupation }\end{array}$ & - \\
\hline 6. Livestock & Livestock holding & Number (Livestock Standard Unit) & $+/-$ \\
\hline 7. Landholding & Landholding or Farm size & Area in Hectares & + \\
\hline 8. PersonalLocalite & $\begin{array}{l}\text { Frequency of contact with } \\
\text { Personal Localite sources of } \\
\text { information }\end{array}$ & $\begin{array}{l}\text { The cumulative of scores assigned } \\
\text { on the basis of frequency of contact } \\
\text { with sources of information }\end{array}$ & + \\
\hline 9. PersonalCosmopolite & $\begin{array}{l}\text { Frequency of contact with } \\
\text { Personal Cosmopolite sources of } \\
\text { information }\end{array}$ & $\begin{array}{l}\text { The cumulative of scores assigned } \\
\text { on the basis of frequency of contact } \\
\text { with sources of information }\end{array}$ & + \\
\hline 10. MassMedia & $\begin{array}{l}\text { Frequency of contact with Mass } \\
\text { media sources of information }\end{array}$ & $\begin{array}{l}\text { The cumulative of scores assigned } \\
\text { on the basis of frequency of contact } \\
\text { with sources of information }\end{array}$ & $+/-$ \\
\hline 11. Group & $\begin{array}{l}\text { Involvement of farmer in } \\
\text { farmers' group }\end{array}$ & $\begin{array}{l}=1 \text { if the farmer is a member; } 0=\text { if } \\
\text { not a member of farmers' group }\end{array}$ & + \\
\hline 12. Experience & $\begin{array}{l}\text { Year of } \\
\text { commercial } \\
\text { cultivation }\end{array}$ & Years & + \\
\hline
\end{tabular}

Table 2 Logit regression results on the adoption of recommended technology

\begin{tabular}{|c|c|c|c|c|c|}
\hline Variable $^{\mathrm{a}}$ & Coefficients & $\mathrm{P}>|\mathrm{z}|$ & Robust S. E. & $\mathrm{dy} / \mathrm{dx} \mathrm{b}^{\mathrm{b}}$ & S.E. ${ }^{b}$ \\
\hline Age & 0.001 & 0.975 & 0.028 & 0.000 & 0.007 \\
\hline Gender & 0.832 & 0.115 & 0.528 & 0.201 & 0.121 \\
\hline FamilySize & 0.204 & 0.128 & 0.134 & 0.051 & 0.034 \\
\hline Education* & 0.103 & 0.065 & 0.056 & 0.026 & 0.014 \\
\hline Occupation $* * *$ & -2.207 & 0.000 & 0.579 & -0.493 & 0.105 \\
\hline Livestock & -0.071 & 0.648 & 0.156 & -0.018 & 0.039 \\
\hline Landholding & 1.007 & 0.167 & 0.729 & 0.252 & 0.182 \\
\hline PersonalLocalite** & 0.353 & 0.020 & 0.152 & 0.088 & 0.038 \\
\hline PersonalCosmopolite & 0.184 & 0.160 & 0.131 & 0.046 & 0.033 \\
\hline MassMedia & -0.175 & 0.128 & 0.115 & -0.044 & 0.029 \\
\hline Group $* * *$ & 1.635 & 0.001 & 0.511 & 0.383 & 0.106 \\
\hline Experience $* *$ & 0.159 & 0.035 & 0.076 & 0.040 & 0.019 \\
\hline CONSTANT & -5.392 & 0.001 & 1.581 & - & - \\
\hline \multicolumn{6}{|l|}{ Summary statistics } \\
\hline Number of observations $(\mathrm{N})$ & \multicolumn{5}{|l|}{120} \\
\hline Log likelihood & \multicolumn{5}{|l|}{-56.9692} \\
\hline Wald test (10) & \multicolumn{5}{|c|}{$34.26 * * *\left(\mathrm{Prob}>\mathrm{chi}^{2}=0.0006\right)$} \\
\hline Pseudo $\mathrm{R}^{2}$ & \multicolumn{5}{|l|}{0.3145} \\
\hline Goodness of fit test & \multicolumn{5}{|c|}{ Pearson $\operatorname{chi}^{2}(107)=114.75\left(\right.$ Prob $\left.>\operatorname{chi}^{2}=0.2867\right)$} \\
\hline Area under the ROC curve & \multicolumn{5}{|l|}{0.8451} \\
\hline Overall correct Prediction & \multicolumn{5}{|l|}{$79.17 \%$} \\
\hline \multicolumn{6}{|c|}{$\begin{array}{l}\text { * Significant at } \mathrm{P}=0.10 ; * * \text { Significant at } \mathrm{P}=0.05 ; * * \text { Significant at } \mathrm{P} \geq 0.01 ;{ }^{\mathrm{a}} \text { Definitions for variables as Table } 1 ; \\
\text { b }\end{array}$} \\
\hline \multicolumn{6}{|c|}{ Table 3 Confidence Interval (CI) for significant variables of logit regression at $95 \%$ confidence interval } \\
\hline Variable & Estimate & & & C.I. & Upper C.I. \\
\hline Education & 0.102 & & & & 0.213 \\
\hline Occupation & -2.169 & & & & -1.073 \\
\hline Group & 1.696 & & & & 2.637 \\
\hline Personal Localite & 0.325 & & & & 0.651 \\
\hline Experience & 0.165 & & & & 0.307 \\
\hline
\end{tabular}


Farmer's major occupation significantly but negatively influences the level of adoption of the recommended technology. When a farmer with agriculture as the source of income or job start involving in any off farm job, the probability of the farmer being high adopter decreases by nearly $50 \%$, i.e. if a farmer is involved in off farm profession along with agriculture, the probability of the farmer being high adopter reduced by nearly half. This is because those farmers involved in off farm job give less time for the crop and also they are busy in the secondary job giving less emphasis to cauliflower production. It is also because the farmers and/or their spouses who work off the farm may be less informed about the new technology and thus are less inclined to adopt the technology. Payne et al. (2003) stated from similar research that off-farm work by the operator or spouse has negative relation with the adoption of innovation.

Other variables studied were not significantly influencing the decision to adopt the recommended technology. Among them, numbers of livestock and the contact with mass media sources of information were negatively associated with adoption. Non significant but positively associated variables were age, gender, family size, landholding size and contact with personal cosmopolite sources of information. Though nonsignificantly associated, it is seen that the probability of a farmer being high adopter increases by about $25 \%$ when there is unit increase in the landholding size of the farmer household.

The Table 3 shows up the Confidence Interval (CI) for parameter $\beta$ for the five explanatory variables; Education, Occupation, Group, Personal Localite and Experience in the logistic regression model. The table shows that all the variables that are significant in the logistic model have intervals that not including the 'no effect value' 0 , at the 95\% CI, it helps to develop confidence on the effect.

Only $12 \%$ of the farmers were highly satisfied with their enterprise. The satisfaction was based on the return from cauliflower production. A numbers of constraints were found associated with the adoption of cauliflower production technologies. Major constraints faced by farmers were lack of irrigation facilities, quality seed, fluctuations in the prices, lower farmer's share, drought, disease and pest problem and technical support or extension facilities.

\section{Conclusion and Recommendations}

Among the factors hypothesized to influence the adoption, education, occupation, group membership, farming experience and contact with personal localite sources of information were significant while age, gender, family size, livestock, landholding, personal cosmopolite and mass media were not significant. The scientists and extension agents thus need to focus on the positive determinants of technology adoption while developing any innovation and also during transfer of those technologies to the farmers. Since the ultimate aim of an innovation is to be adopted by the users or clients, it is better to consider the information on the factors that affect the technology adoption before the transfer of technology to the farmers. Along with the agricultural technology, it will be better to suggest for similar activities for the welfare of the socioeconomic factors of the target areas.

\section{References}

Adjaye, JA. 2008. Factors Affecting the Adoption of Soil Conservation Measures: A Case Study of Fijian Cane Farmers. Journal of Agricultural and Resource Economics. 33(1): 99-117.

Bose SP. 1964. The Adopters. Calcutta, India: Department of Agriculture, Extension Bull No. 2, Government of West Bengal, Calcutta.

CBS. 2007. Population Profile of Nepal. Kathmandu, Nepal: Central Bureau of Statistics, Government of Nepal.

CBS. 2008. Statistical Pocket Book Nepal. Kathmandu. Nepal: Central Bureau of Statistics, Government of Nepal.

Chambers R. 1994. The Farmers' Approach to Adoption of Agricultural Innovation and Agronomic Research. Paris, France: Edition Karthala.

Adjaye, JA. 2008. Factors Affecting the Adoption of Soil Conservation Measures: A Case Study of Fijian Cane Farmers. Journal of Agricultural and Resource Economics. 33(1): 99-117.

Bose SP. 1964. The Adopters. Calcutta, India: Department of Agriculture, Extension Bull No. 2, Government of West Bengal, Calcutta.

CBS. 2007. Population Profile of Nepal. Kathmandu, Nepal: Central Bureau of Statistics, Government of Nepal.

CBS. 2008. Statistical Pocket Book Nepal. Kathmandu. Nepal: Central Bureau of Statistics, Government of Nepal.

Chambers R. 1994. The Farmers' Approach to Adoption of Agricultural Innovation and Agronomic Research. Paris, France: Edition Karthala.

Chi TTN. 2008. Factors Affecting Technology Adoption among Rice Farmers in the Mekong Delta Through the Lens of the Local Authorial Managers: An Analysis of Qualitative Data. OMONRICE 16. Vietnam: Cuu Long Delta Rice Research Institute (CLRRI): 107-112.

DeSouza G, Cyphers D, Phipps T. 1993. Factors Affecting the Adoption of Sustainable Agricultural Practices. Agricultural and Resource Economics Review, Northeastern Agricultural and Resource Economics Association 22(2): 159-165.

Dongol BBS. 1979. Factors Affecting Adoption of Improved Agricultural Practices of Paddy Cultivation in Chitwan District of Nepal (Unpublished). Department of Extension Education. SKN College of Agriculture. University of Udaipur.

Dongol BBS. 2004. Extension Education. Kathmandu, Nepal: Pratibha Singh Dongol.

Gross N. 1949. The Differential Characteristics of Adopters and Non-Adopters of an Improved Technological Practice. Rural Sociology: 14

Gujarati DN. 2003. Basic Econometrics. New York, USA: McGraw-Hill

Hosmer DW, Lemeshow S. 2000. Applied Logistic Regression, New York, USA: John Wiley \& Sons.

Kattel RR. 2009. The Impact of Coffee Production on Nepali Smallholders in the Value Chain (Unpublished). Institute of Environmental Economics and World Trade, Leibniz Universitat. Hannover, Germany.

Kavia FY, Mushongi CC, Sonda GB. 2007. Factors Affecting Adoption of Cassava Varieties: A Case of Cassava Mosaic Disease Tolerant Varieties in Lake Zone Regions - Tanzania. Proceedings of African Crop Science Conference, African Crop Science Society: 8 .

Lawal JO, Oluyole KA. 2008. Factors Influencing Adoption of Research Results and Agricultural Technologies Among Cocoa Farming Households in Oyo State, Nigeria. International Journal of Sustainable Crop Production. 3(5): 10-12. 
Lionberger AF. 1960. Adoption of New Ideas and Practices. Ames, Iowa: The Iowa State University Press.

Makokha SN, Karugia J, Staal S, Kosura O. 2007. Analysis of Factors Influencing Adoption of Dairy Technologies in Western Kenya. Proceedings of AAAE Conference. AAAE Ghana: 209213.

Mussei A, Mwanga J, Mwangi W, Verkuijl H, Mongi R, Elanga A. 2001. Adoption of Improved Wheat Technologies by SmallScale Farmers in Mbeya District, Southern Highlands, Tanzania. Mexico: International Maize and Wheat Improvement Center (CIMMYT) and the United Republic of Tanzania

Payne J, Cornejo JF, Daberkow S. 2003. Factors Affecting the Likelihood of Corn Rootworm Bt Seed Adoption. Washington D.C, USA: Western Agricultural Economics Association, Economic Research Service, USDA.
Roger EM. 1965. Diffusion of Innovations. New York: The free Press: 76

Sebadieta RB, Terblanche SE, Ngomane T. 2007. Factors Influencing Adoption and Non-adoption of Acquired Knowledge and Technologies at Denman Rural Training Centre, Gaborone Agricultural Region, Botswana. South African Journal of Agricultural Extension. 36: 124-143

VDD. 2007. Annual Report. Lalitpur, Nepal: Vegetable Development Division, Department of Agriculture

VDD. 2008. Annual Report. Lalitpur, Nepal: Vegetable Development Division, Department of Agriculture.

Ward CE, Vestal MK, Doye DG, Lalman, DL. 2008. Factors Affecting Adoption of Cow-Calf Production Practices in Oklahoma. Journal of Agricultural and Applied Economics. 40:3: 851-863 